\title{
ÉL, TÚ Y YO: Deus e o Diabo na Terra do sol
}

Víctor Amar (CÁDIZ)

Jenipapo Mulungú

Mata, seca, céu azul

O quipá faxeiro e o mandacaru

Pele de onça preta

Tatu, tamanduá

Calango comendo batata tiú

Jararaca armada

Pé de Jacurutu

(Paulo Sores. Caatinga)

\section{Él. Un análisis incompleto de la película}

Analizar un film requiere un rigor extraordinario. Se ha de conocer en profundidad sobre los contenidos a abordar y se ha de tener, igualmente, un saber contextualizado de los aspectos a estudiar. En el primer caso, su conocimiento nos lleva a la realización del posible ejercicio de creación, inspirado en la sensatez. Mientras que el segundo, es un quehacer de recreación donde los matices cargan las tintas y establecen las tonalidades sobre aquel lienzo dibujado con la intención que deja ver el dibujo, que no es otra cosa que la propia belleza.

Para abordar una película hace falta conocerla en todas sus dimensiones y no solo ser un advenedizo y poder llegar a perderse, y hacer perderse, entre las anécdotas fugaces conllevando una sensación de pérdida de tiempo a raíz del uso, abuso y maluso de insignificantes cuestiones que nada o poco aportan. El lector-espectador sabe que 
el cine también se escribe. Que hay una escritura, también, después de su realización. En este sentido, la crítica periodística y especializada se encarga de ello pero, de la misma manera, la investigación aporta a este discurso y contribuye a la divulgación y consideración de la obra cinematográfica.

Con todo, nuestra aportación post-realización fílmica es un ejercicio interpretativo (con unos brotes biográficos) de una obra de arte en blanco y negro: Deus e o Diabo na Terra do Sol (1964). Su director, Glauber Rocha (Bernardet, 1991), en España era conocido por una minoría de cinéfilos. Veamos con más detenimiento esta reseña inicial. Las grandes ciudades de España tenían poca distribución del cine brasileño y, concretamente, esta película se estrenó en Barcelona en mayo de 1968. Los que nacimos en aquellos años nos incorporábamos a la Universidad en la década de los 80, y en nuestras clases de cine, apenas accedíamos a estas manifestaciones que además de lejanas hablaban en portugués. Sabedores de su existencia era difícil asistir a una producción de Brasil. La colonización del cine norteamericano se había afianzado en el gusto del español medio que, igualmente, reaccionaba ante el cine made in Spain de rancio sabor y solo en las salas llamadas de 'arte y ensayo' había un espacio para este cine foráneo o de calidad, al igual que en puntuales festivales. Asimismo, los cineclubes tenían claro su consigna de luchar conscientemente a través de la lección magistral del imago en movimiento. Entonces, la lejanía, la colonización del gusto y la herencia del cine europeo en las salas tangenciales a los circuitos de exhibición colmaban el panorama del cine en España de los años 60 y 70. Pero no podemos olvidar la labor de las revistas de aquellos años del postfranquismo, la transición y el advenimiento de la democracia en Espańa. Parangonando a los franceses e italianos las revistas de cine hicieron su labor y quien no podía ver una película, al menos, podía leer sobre ella. Por ello, insistimos, en la singularidad de la escritura de cine después de su realización y estreno.

En este contexto introductorio, hablar de Glauber Rocha es complicado, al menos, desde el contexto español y a tenor de estas características genéricas que hemos expresado. Aunque, a decir verdad, Glauber pasó un tiempo en España en sus años de exilio e, incluso, realizó aquí la película Cabezas Cortadas (1970) con guión de Augusto Martínez Torres y Josefa Pruna, con la participación del prestigioso actor español Francisco Rabal, sobre una alegoría de inspiración buńuelesca contra las dictaduras aún en vida del caudillo español Francisco Franco (Martínez Torres, 1970).

Con todo, y con respecto a la cinta Deus e o Diabo na Terra do Sol, el ser extranjero no elude las responsabilidades pues el análisis requiere un enfoque y una metodología en el abordaje que facilite la discusión y la comprensión. La película es más que un drama. Versa sobre una reflexión transcendental en un espacio definido como es el 
Sertão (Xavier, 1983; Cunha, 1985; Rosa, 1986), con unos personajes que parecen salir de la herencia de la literatura de cordel y el imaginario colectivo. Un largometraje con un reconocimiento de la crítica internacional y premiado en diferentes festivales (incluso en Cannes), que lanzó al exterior la cinematografía novista de un grupo de jóvenes de izquierda en el Brasil de 1964 (Amar, 1993). Es decir, estableciendo un posible itinerario de la película, diríamos que se inicia en el estado de Bahia, recorre el sur del país y recibe un reconocimiento en Francia que le abre las puertas a todo el mundo. En este sentido, el eco del cine llega antes a los espectadores ávidos a través del papel que por el celuloide.

Si él es la obra, la cual le damos la categoría de agente en acción simbolizando la tercera persona del singular; ésta será la manera de acercarnos y conocer a la cinta. Es decir, estamos ante una forma masculina del pronombre personal que hacemos coincidir con la película. Sin olvidar, en este caso, que él no es nada sin un contexto de acercamiento a través del tú y el yo. No obstante, las otras formas del pronombre son en plural, donde se incluyen, como no podría ser de otro modo, el ellos, el vosotros o el nosotros.

Esta película simboliza una metáfora de algo en apariencia real. Un parecer, la del propio director, que mira más allá de la realidad filmada pues lo universal se apodera del todo y vira una suposición ideal, sońada de una verdad a medias, pues no es una omisión pero tampoco un olvido y se trata de una película sobre unos hechos que trascienden, lejos de su verismo o veracidad. Lo que hay es lo que es y el resto lo ha de saber interpretar el espectador. Glauber Rocha se adelanta a su tiempo, pues le pertenece desde la temática que trata a la gente que se debe, sin olvidarnos de los duros años dictatoriales en que la producción se realiza. Quien lo tachara como precursor del futuro no se equivocaba pues su cine siempre se escribió en este tiempo verbal, incluso obras anteriores como Barravento (1962) o posteriores como O dragáo da maldade contra o santo guerreiro (Antonio das Mortes), (1969).

En Deus e o Diabo na Terra do Sol el delirio se torna en coherencia interna, pues la confusión por alucinaciones se evidencia y se suscribe a través de reiterados pensamientos ilógicos que rozan lo surreal. Y todo, en la mayoría de los espectadores, se traduce en un devenir hacia la burla, el rechazo o la incomprensión. Sin embargo, la obra permanece y siembra la ternura de una mirada en la protagonista enamorada, el rechazo ante la insolencia de un monstruo hecho hombre que depreda al propio ser humano, el renegar a un santón incontrolado o el no empatizar, en todo momento, con el protagonista a quien le falta capacidad para acabar con todo lo que no vale para llevar una vida más justa y armónica. 
Esta película de 1964 no es solo una visión infundada pues tiene su desarrollo y su conclusión; posee su metodología idónea de desarrollo y un amplio discurso que enlaza con la polisemia de la realidad y la estética de aquel entonces. Estamos ante una tesis, una lección magistral. Una obra de arte que no solo hay que verla sino, también, sentirla. Un espectáculo ocular compartido para su disfrute desde la perspectiva de los sentidos y los sentimientos. Para llorar y reír, para pensar y olvidar... como la vida misma. Estamos enjuiciando un comportamiento filmado, una sensibilidad que no nos pertenece y, por ello seguidamente, compartimos la palabra con el tú.

Tú. Un punto de vista del otro

Tú, en su segunda acepción según la Real Academia de la Lengua Española, cabría traducirse en la designación de una persona indeterminada. Ese tú existe, piensa y actúa. Conoce el cine y la película. Habla con propiedad serenamente, dice y reflexiona, analiza y da a comprender. Un tú ideal porque tiene ideología. Un tú sabio pues comparte lo que conoce. Un tú que mantendremos en el anonimato. No es un actor secundario, no es un autor de prestigio. No está ignorado, no anda escondido. Es como el ciego en la película, que lo sabe y nos lo cuenta. A veces, hay que preguntárselo y en otras ocasiones, su generosidad porosa revela su patrimonio intelectual y popular que sin pudor es compartido.

El tú es, también, fortaleza. Tal vez, estamos ante un hombre a los que llaman de cabra macho. Agreste y fornido. Envuelto en una capa grande y espaciosa cubre su cuerpo pero, igualmente, su alma. Lo primero está sujeto a su ego, mientras que la otra huye lejos cuando puede y busca un camino hacia otro lugar, de aquí para allá, pues no está en paz consigo mismo. Una geografía que considera que le pertenece, si la mira desde el cielo, pero en la tierra la padece y la hace padecer. Un hombre con sombrero que cubre su pensar, como si lo tuviese; y además tiene barba para tapar su desnudez y camina mirando a un lugar u otro para generar zozobras y evidenciar que está preparado y dispuesto para matar. Supongamos que hablamos de Antônio das Mortes.

El otro tú protagonista es también masculino y responde al nombre de Manoel y está casado. Sufre y es maltratado. Cuando tiene lucidez sufre y cuando ignora hace sufrir. Caminante o errante. Andariego o transeúnte. Estamos ante una figura fundamental para la comprensión del largometraje que en una eclosión a modo de carrera final confunde Sertão y mar. Quién lo diría, Manoel, siendo el protagonista aparece como coadyuvante. Le usurpan su protagonismo y nos da la impresión que hasta lo cede, sin más y sin mostrar vehemencia. 
Buscando en el tú encontramos a uno que se escribe con letra de santón y se torna sabelotodo. Da miedo pues tiene pavor. No ama, sino teme, a su dios menor como a los seres humanos que cohabitan junto a él. Manipula la ignorancia de quien le aprecia y dice lo qué tienen que hacer. No mira a los ojos pues están turbados por tanto odio. Se dice humano aunque se esconde, en el fondo, un mortal non grato. Su final no se hace esperar y ella, la mujer de Manoel, lo matará explicando así que no puede continuar fastidiando en un mundo donde se anhela la predilecta justicia social. Su universo está repleto de indolencia e insolencia.

Y Rosa no se declina con rosae. Rosa es simplemente eso, una mujer. Probablemente, una rosa que se marchita. Una mujer que más que maldita es una sufridora. Tal vez, buscando un símil con la literatura de Federico García Lorca, una especie y especial Mariana Pineda amante de Don Pedro de Sotomayor. Un amor al que sigue y un sentimiento que no se puede explicar pues acompaña a los dictados del corazón. Sufre y sigue a su amado Manoel. Y nos imaginamos si se preguntaría: ¿para qué? No es la Carmen de Prosper Mérimée, pero tienen en común que ama para ser amada, llora pues padece y se olvida para sobrevivir.

Corisco pasa de la ficción a la acción. Hombre de la tierra. "Caminante no hay camino se hace camino al andar", diría de él Antonio Machado pero sabe qué hacer y cómo resolver los asuntos. Probablemente, la mayoría no compartiésemos sus andanzas y resolución del conflicto pero es fundamental para entender la película. Arraigado al lugar, camina por su tierra, ve lo que otros no ven y padece pues siente.

El tú también es (son) Sebastião, Dadá o el coronel; personajes imprescindibles para que las acciones tengan sus propios lubricantes. Ejes entre secuencias, junto con Moraes o el padre van y vienen, aparecen y desaparece pues son gente que padecen calladamente. No tienen mayores estrategias resolutivas que el silencio o la brusquedad. No han desarrollados otras habilidades sociales que la mirada al frente o el soslayo. Y nos preguntamos: ¿pasan por el mundo o el mundo pasa por ellos? Es como un tú en plural, al que referirte puedes como vosotros o ustedes.

Por último, hablamos de otro tú en plural pues si el diablo/diabo es Corisco y dios/deus el santón Sebastião no cabe la particularidad. Ahora bien, en el espejo de la multitud se refleja lo confeccionado en sus pieles y rostros: la pertenencia a un grupo acéfalo y ágrafo. Quizás, ellos no piensan o, mejor dicho, son llevados a pensar como los otros quieren que piensen, sin hablar o manifestar descontento. Son sus seguidores y secuaces. Ellos dejan entrever una relación de amor y odio, confeccionándose como las dos caras de una misma moneda. Un pueblo sufridor que no sabe como redimirse. Sigue y no consigue, parte y no comparte y todos de nuevo con la misma pregunta: 
¿para qué? Hacia dónde van o mejor dicho hacia dónde los llevan. Se trata de un pueblo que no es garante de su destino. Son extras no extraordinarios; son, en este sentido, imprescindibles.

En segunda persona hemos intentado hablar de ellos: los protagonistas. Éstos dan orden y sentido al guión que luego es expuesto al enjuiciamiento popular en la gran pantalla del cine. La opinión, sea crítica, reflexiva o analítica, no se hace esperar. La empatía o antipatía tampoco se oculta y todo vira un dislate por entender lo que nos debe ir llevando hacia la comprensión de unos hechos de inspiración histórica, basados en la herencia de referencia del nordeste y recreados por la mente de un genio llamado Glauber, que nos hace reinterpretarlo más allá de sus cincuenta años de exhibición, de existencia fílmica.

Tú joven director, por aquel entonces con unos veinte y cinco años, de Bahia para Rio, fuiste sensible y consciente de la situación política que atravesaba aquel tu país de dimensiones continentales (Avellar, 2002). Que te atreves a escribir y grabar cine con el éxito descrito de quien es capaz de aglutinar la realidad de un subcontinente llamado Brasil en una película que dicen de difícil comprensión pero que refleja en sus metáforas la necesidad de dar a comprender lo que sucedió, sucede y sucederá si no se enmienda o entiende lo acontecido. Una película que envejece fiel a su devenir pero no se consume o languidece pues cada vez que se ilumina hace estallar filamentos de lucidez sobre el espectador que ha de dejar de ser público, que no debe solo ver sino mirar y aprender a separar con la mirada. De lo contrario lo vera todo en blanco o negro y perderá los muchos tonos y matices del gris. Hablará de ella como de una cinta hermética y obtusa. Tú espectador de hoy en día deberías, en primer lugar, sentirla o emocionarte y luego ya hablaremos de cine, literatura, historia, política, economía, etc.

\section{Yo. O sobre mi opinión inconsistente}

Aquí y ahora será mi opinión la que prevalezca. Lejos de una visión genérica o de las particularidades de los protagonistas o del largometraje. En este sentido, la perspectiva se cierne sobre lo que vi o entendí. Lo primero es decir que antes de ver la película conocí Brasil. Un país inmenso, plural y extenso en cultura y tradiciones. No es igual vivir en el sur que en el nordeste. No es lo mismo llegar de nuevo que ser oriundo. El hecho de vivir en Brasil exige, desde mi consideración, visitar otros estados al que uno pueda residir. Los espacios de completan pero, me da la impresión, que no se complementan. Las diferencias se explican viajando pero no se comprenden no solo por las contradicciones sino por la naturaleza propia de la diversidad. 
Descubrir la similitud entre mi lugar de nacimiento y mi espacio de acogida, de Cádiz al sur de España en Andalucía a Sao Paulo y Rio de Janeiro pasando por Bahia y Pernambuco, invitan a seguir viajando pues en el camino se descubre a autores como el bahiano Esmeraldo Lopes y uno encuentra o suscribe las similitudes entre lo que ve, lee y dejó en su tierra natal. Pertenecemos a la parte "olvidada" de lo impuesto pero somos un baluarte de historias, poetas y generosidad.

La Andalucía profunda se asemeja con la Bahia retratada en la cinta. Por ejemplo, véase a Federico García Lorca con aquellos dramas luctuosos de Bernarda Alba o la poesía de sentir universal pues el amor así se extrapola de un lugar a otro y no hay diferencia si es un gitano o una morena llamada Gabriela en la pluma de Jorge Amado. La Andalucía de litoral, a la que pertenezco y en la que me encuentro, tiene posibles tintes más cercanos a su capital, Salvador. Aquí el carnaval tiene otro son y el dulce balanço en el caminar, también para la inspiración de los cinemanovistas, se bambolea al aire de levante, un viento que nos visita asiduamente y que desde tiempos de los antiguos fenicios sirvió para la navegación y, siguiendo con la metáfora de Glauber Rocha, para "renovarse”.

La Carmen andaluza puede que experimentase el amor como aquella Maria Bonita del nordeste. El terrateniente del sur de España, aquí llamado señorito, mucho tiene de parecido con el coronel del nordeste y el bandolero es casi idéntico al cangaceiro (Jasmin, 2006). Aquí no existe una Iracema tal como la imaginara José de Alencar pero hay unas mujeres espectaculares en el teatro de los Hermanos Álvarez Quintero. Soy del lugar del "marinero en tierra" según el poeta Rafael Alberti. Al igual que ustedes lo son de la otra bahía, si es que existiese además de la de Cádiz... la del Brasil, y disfrutan de ser herederos de la sensibilidad de, por ejemplo, João Cabral de Melo Neto.

Y lo mío con lo de ustedes forjó mi sensibilidad por querer aprender y desaprender. Lo mío y lo de ustedes gestó mi forma de vivir y convivir. Yo y ustedes hicieron que sea y sienta el cine de Glauber Rocha como una continua obra de arte en construcción. Tal vez, está inacabada para que en nuestras retinas la terminemos y sigamos buscando por entre los personajes, situaciones o diálogos lo que nos quería transmitir.

Lejos de que me interpreten en este aparatado del yo como un gesto de presunción, decirles que admito lo mucho que aún me queda por conocer y saber de ambas bahías o Brasil y no digamos nada sobre cine y todavía menos sobre Glauber Rocha y la película en la que nos hemos detenido. Una cinta emotiva y llena de incógnitas para que un foráneo, aunque no me considero un intruso, pueda hablar de ella con cariño y entusiasmo pero, siempre, respetuosamente. Lo que no quita que intente aportar mi "granito de arena" y no como aquellos capitanes de arena de Jorge Amado que se debatían, allá por el medio siglo, entre el amor y el rechazo... Y sí como uno que llega 
con la intención de aprender del cine, del nordeste brasileño, de Glauber y de todos ustedes. Soy como el eterno aprendiz que no se despega del maestro pues deseo imitarles con meridiana exactitud, para ser feliz. Soy un perdido amigo que aparece amante de lo bueno del cine de Glauber Rocha y cada vez que se asoma a la película Deus e o Diabo na Terra do Sol (Alves de Souza Monzani, 2005) se hace más socrático a partir del "solo se que no se nada". Un dios que no termino de encontrar, un diablo que se hace hombre un una tierra del sol donde el semiárido ha generado una cultura envidiable, y con un patrimonio apreciable, que el cine hace que se conozca, reconozca y valore.

De la película Deus e o Diabo na Terra do Sol aprecio su puesta en escena. Es, sencillamente, seductora. Considero un excelente trabajo el realizado por equipo actoral y la dirección de actores. La historia contada es parecida a las que narran los cordelistas y los repentistas. Los rostros de los actores secundarios y extras son verdaderos, fiel a las gentes del lugar. Lo universal de la historia es que se funde con la piel de los que sufrieron o sufren la opresión, la ignorancia o la omisión... y eso ha sucedido o sucede en cualquier parte del mundo.

Yvolviendo a ver la película de Deus e o Diabo na Terra do Solsuscribo públicamente, y una vez más, que me sigue seduciendo este país llamado Brasil, una región que ya fue perfectamente descrita por Euclides de Cunha y un estado, Bahia, que sorprende en todo el amplio sentido el término (desde que atrapa o asombra, desde que produce admiración o conmueve). Y siendo fiel a mi propia sensibilidad por la literatura me apasiona el cordel y, por ello, la tradición visualizada en esta película a través del ciego.

Continuando con los personajes no podemos olvidarnos del ciego Julio, testimonio, memoria del pueblo, que trasmite la tradición oral, mediante el cancionero. Podemos considerarlo como fuera de la acción; acompaña los acontecimientos pero nunca actúa, al igual que el propio pueblo (Amar, 1993: 114).

Una vez más Brasil y Bahia, el cine y Glauber Rocha... y esta película en particular me han dado una lección magistral de vida, pues no es igual ver la cinta ahora que cuando la vi por primera vez. Ella apenas ha envejecido pero yo, ineludiblemente, peino canas.

\section{$\operatorname{son} 2$}

\section{REFERENCIAS}

Alves de Souza Monzani, J. M. (2005). Gênese de Deus e o Diabo na Terra do Sol. São Paulo y Salvador:

Annablume, Fapesp, Fundação Gregório de Mattos y UFBA.

AMAR, Victor. El Cine Nuevo Brasileño (1954-1974). Madrid: Dykinson. 1993. 
AVELLAR, José Carlos. Glauber Rocha. Madrid: Cátedra, 2002.

BERNARDET, Jean-Claude (Org.). Glauber Rocha. São Paulo: Paz e Terra, 1991.

CUNHA, Euclides da. Os sertôes: campanha de Canudos. São Paulo: Brasiliense, 1985.

JASMIN, É. Cangaceiros. São Paulo: Terceiro Nome, 2006.

MARTINEZ TORRES, A. Glauber Rocha y Cabezas Cortadas. Barcelona: Anagrama, 1970.

ROSA, João Guimarães. Grande Sertão: veredas. Rio de Janeiro: Nova Fronteira, 1986.

XAVIER, Ismail. Sertão mar: Glauber Rocha e a estética da fome. São Paulo: Brasiliense, 1983.

\section{Resumém}

La historia se vive y, por tanto, se vuelve a recordar. En este caso con tintes biográficos y tiene al cine brasileńo como pretexto en el contexto del film "Deus e o día o na Terra do sol" del director bahiano Glauber Rocha. Entonces, él, tú y yo son partes del texto que para el autor, en el contexto de España, es y fue el pretexto para conocer Brasil y su cine, la cultura y su gente.

\section{Resumo}

Uma história que se vive se continua vive-la. Este texto de traços biográficos tem no cinema brasileiro o pretexto para rememorar a descoberta do filme "Deus e o Diabo na Terra do Sol", do diretor baiano Glauber Rocha. Então ele, tu e eu são partes do mesmo texto que para o autor no contexto da Espanha é e foi um pretexto para conhecer o Brasil e seu cinema, sua cultura e sua gente.

Victor Amar, doutor e professor do Departamento de Didáctica da Universidade de Cádiz, Espanha; diretor do grupo de pesquisa: Educação e Comunicação, da Junta de Andalucia; é coordenador da revista: http Educação e Comunicação. 